\title{
Altered Wnt5a expression affects radiosensitivity of non-small cell lung cancer via the Wnt/ $\beta$-catenin pathway
}

\author{
JUNZHE LI ${ }^{*}$, SHIJIE XU ${ }^{2 *}$, HUA DONG $^{3}, \mathrm{XIAYU} \mathrm{WU}^{4}$, LI-HONG WANG ${ }^{2}$ and XIANHUA XU ${ }^{2,4}$ \\ ${ }^{1}$ Department of Thoracic Surgery; ${ }^{2}$ Medical Research Center; ${ }^{3}$ Hainan Cancer Prevention and Treatment Center; \\ ${ }^{4}$ Department of Pathology, Hainan Cancer Hospital, Affiliated Cancer Hospital of \\ Hainan Medical University, Haikou, Hainan 570312, P.R. China
}

Received January 19, 2021; Accepted July 19, 2021

DOI: $10.3892 / \mathrm{etm} .2021 .10927$

\begin{abstract}
It has been reported that upregulation of wingless-type protein 5a (Wnt5a) is associated with poor prognosis in patients with non-small cell lung cancer (NSCLC). Wnt5a expression is often upregulated in radiation-resistant NSCLC cells. However, the biological functions or molecular mechanisms of radiosensitivity in NSCLC remain unknown. In the present study, MTT assay and flow cytometric analysis were performed to assess the effect of overexpression or knockdown of Wnt5a and/ or radiation on the proliferation and apoptosis of NSCLC cells. Furthermore, western blot analysis was performed to detect canonical Wnt signaling ( $\beta$-catenin) in H1650 and A549 cells. The results demonstrated that Wnt5a knockdown combined with irradiation inhibited proliferation and induced apoptosis in NSCLC cells compared with Wnt5a knockdown or radiotherapy alone. In addition, the combination of Wnt5a knockdown and irradiation decreased nuclear and increased cytoplasmic $\beta$-catenin expression in H1650 and A549 cells, the effects of which were reversed following overexpression of Wnt5a. The combination of overexpressing Wnt5a and irradiation resulted in significant tumor regression, while $\beta$-catenin knockdown reversed Wnt5a overexpression-induced NSCLC cell proliferation. Taken together, these results suggest that Wnt5a may be involved in the activation of $\beta$-catenin-dependent canonical Wnt signaling, and thus may influence the effectiveness of radiation therapy in NSCLC.
\end{abstract}

Correspondence to: Dr Xianhua Xu, Department of Pathology, Hainan Cancer Hospital, Affiliated Cancer Hospital of Hainan Medical University, 6 Changbin West Fourth Street, Xiuying, Haikou, Hainan 570312, P.R. China

E-mail:sunhwa@126.com

*Contributed equally

Key words: non-small cell lung cancer, Wnt5a, radiosensitivity, Wnt/ $\beta$-catenin pathway

\section{Introduction}

Lung cancer is the leading cause of cancer-associated mortality worldwide for 36 cancers ( $18.0 \%$ of the total cancer deaths) in 185 countries in year 2020 (1), and non-small cell lung cancer (NSCLC) accounts for up to $80 \%$ of total pulmonary malignancies (2). Radiotherapy is the most common treatment method used for localized lung cancer; it is non-invasive and well-tolerated $(3,4)$. In patients with NSCLC, radiotherapy plays a key role in local treatment by inducing DNA damage, triggering cell cycle arrest and apoptosis of tumor cells $(5,6)$. However, radioresistance remains an obstacle in achieving successful treatment. Thus, novel therapeutic strategies are required to improve the effectiveness of radiotherapy for patients with NSCLC.

A previous study reported that the wingless-type (Wnt) pathway is associated with radioresistance in $\operatorname{NSCLC}(7,8)$. It has been reported that Wnt5a expression is upregulated in different types of cancer, including gastric, pancreatic and prostate cancer (9-11). A previous study demonstrated that silencing Wnt5a expression decreases migration, invasiveness and epithelial-to-mesenchymal transition (EMT) of NSCLC cells; these effects are reversed following overexpression of Wnt5a (12). Furthermore, preclinical and clinical studies have reported that the combination of gene therapy and conventional anticancer therapy can improve the therapeutic benefits (13-16). Although Wnt5a expression is upregulated in radioresistant NSCLC cells (17), whether Wnt5a promotes radioresistance in NSCLC cells remains unclear.

The present study aimed to investigate the efficacy of overexpression or knockdown of Wnt5a combined with radiotherapy in NSCLC cells. In addition, it has been reported that Wnt5a overexpression promotes the EMT and metastasis of pancreatic cancer cells through the $\beta$-catenin-dependent canonical signaling (9). Thus, the study also investigated whether the $\mathrm{Wnt} / \beta$-catenin pathway was relevant in mediating radioresistance in NSCLC cells.

\section{Materials and methods}

Cell culture. The human NSCLC cell lines, H1650 (cat. no. CRL-5883) and A549 (cat. no. CCL-185) were purchased from the American Type Culture Collection. Cells 
were maintained in RPMI-1640 medium (Thermo Fisher Scientific, Inc.) supplemented with $10 \%$ (w/v) fetal calf serum (Gibco; Thermo Fisher Scientific, Inc.) and 1\% (w/v) penicillin/streptomycin in culture dishes, at $37^{\circ} \mathrm{C}$ with $5 \% \mathrm{CO}_{2}$. Cells were seeded into six-well culture plates at a density of $5 \times 10^{5}$ cells/well.

Cell transfection. For the knockdown of endogenous Wnt5a expression in NSCLC cells, small interfering (si)RNAs were used. For transfection, 1x10 $10^{5}$ A54 and H1650 parental cells were seeded into six-well plates and cultured overnight at $37^{\circ} \mathrm{C}$ with $5 \% \mathrm{CO}_{2}$ until they reached $80 \%$ confluence. The Wnt5a siRNA expression cassette was subcloned into the pcDNA6 expression vector (Invitrogen; Thermo Fisher Scientific, Inc.). The target sequence was 5'-GTTTTGGCCACTGACTGA-3'. For overexpression of Wnt5a, sequences were amplified by PCR and inserted into pcDNA6.2 vector to generate fusion plasmids, namely Wnt5a and pcDNA empty vector as the control. The ratio of the plasmid to the transfection reagent was $1 \mu \mathrm{g}: 3 \mu \mathrm{l}$. Transfection was performed at room temperature using EzWay ${ }^{\mathrm{TM}}$ Transfection Reagent according to the manufacturer's instructions (Invitrogen; Thermo Fisher Scientific, Inc.). To assess the role of $\beta$-catenin, H1650 and A549 cells were transfected for $24 \mathrm{~h}$ with si- $\beta$-catenin $(20 \mathrm{nM}$; Shanghai GenePharma Co., Ltd.; forward, 5'-CATGUGUTGGUAAGC UCUA-3' and reverse, 5'-GCAACAGTTGCAGAGAGGU-3'). A non-specific scramble siRNA was used as a negative control (20 nM; Shanghai GenePharma Co., Ltd.; forward, 5'-AUG CUGATCAGUGUCGATU-3' and reverse, 5'-CAGAGAGCT CGUGAGAGTA-3'). Transfection efficiency was determined via western blotting and reverse transcription-quantitative PCR (RT-qPCR). Subsequent experiments were performed $48 \mathrm{~h}$ post-transfection.

Radiation treatment. Cell irradiation was performed using a Varian 21EX (Varian Medical Systems) linear accelerator with a coverage field of 10x10 cm. H1650 and A549 cells were cultured in 12-well culture plates $\left(1 \times 10^{4}\right.$ cells/well) and were treated for $24 \mathrm{~h}$ with $0,2,4,6$ or $8 \mathrm{~Gy}$ of irradiation at a dosage rate of $100 \mathrm{MU} / \mathrm{min}$ and a source-to-surface distance of $100 \mathrm{~cm}$.

Cell proliferation assay. Cell proliferation was assessed via MTT assay (Sigma-Aldrich; Merck KGaA). At $48 \mathrm{~h}$ post-transfection, $\mathrm{H} 1650$ and A549 cells were irradiated (0, 2, 4,6 or 8 Gy in a single fraction), cultured in 96 -well culture plates $\left(5 \times 10^{3}\right.$ cells/well $)$ and incubated for 5 days at $37^{\circ} \mathrm{C}$ with $5 \% \mathrm{CO}_{2}$. An aliquot of $10 \mu \mathrm{l} \mathrm{MTT}$ solvent ( $5 \mathrm{mg} / \mathrm{ml}$ in PBS) was added to each well. Following incubation for $2 \mathrm{~h}$ at $37^{\circ} \mathrm{C}$, and then $100 \mu \mathrm{l}$ isopropanol with $40 \mathrm{mM} \mathrm{HCl}$ was added to each well to dissolve formazan crystals. Optical density (OD) was measured at wavelengths of 560 and $620 \mathrm{~nm}$, using a measurement parameter editor (Tecan Group, Ltd.). Cell viability was expressed as OD value of the transfected cell/ OD value of background control (untransfected cells).

Colony formation assay. H1650 and A549 cells were irradiated $(0,2,4,6$ or $8 \mathrm{~Gy}$ in a single fraction) $48 \mathrm{~h}$ post-transfection and subsequently seeded into 6-well plates at a density of $1 \times 10^{3}$ cells/well. The RMPI-1640 medium (Thermo Fisher
Scientific, Inc.) was replaced every day and cells were incubated for 14 days at $37^{\circ} \mathrm{C}$ with $5 \% \mathrm{CO}_{2}$. After 14 days, cells were fixed with $4 \%$ paraformaldehyde in PBS for $30 \mathrm{~min}$ at room temperature and stained with crystal violet $(0.4 \mathrm{~g} / \mathrm{l}$; Sigma-Aldrich; Merck KGaA) at room temperature for $30 \mathrm{~min}$. The number of colonies (determined as containing $>50$ cells) was counted manually under a light microscope (magnification, $\mathrm{x} 10)$. The surviving fraction $(\%)$ was calculated as follows: Colony forming efficiency $=$ number of colonies formed following irradiation treatment/number of cells seeded x100. All experiments were performed in triplicates and repeated three times.

Cell apoptosis assay. Cell apoptosis was determined via Annexin V-FITC and PI staining. Following $24 \mathrm{~h}$ irradiation, H1650 and A549 cells were seeded into 24-well plates at a density of $5 \times 10^{4}$ cells/well and resuspended in $100 \mu \mathrm{l}$ binding buffer (10.0 HEPES, $140.0 \mathrm{NaCl}$ and $2.5 \mathrm{mM}$ $\mathrm{CaCl}_{2} ; \mathrm{pH}$ 7.4). The cells were subsequently stained with $5 \mu \mathrm{l}$ Annexin V-FITC and $5 \mu \mathrm{l}$ PI using a FITC Annexin V Detection kit (BD Biosciences) in the dark at room temperature for $15 \mathrm{~min}$, according to the manufacturer's protocol. Cell apoptosis was analyzed via flow cytometry (BD FACSCanto ${ }^{\mathrm{TM}}$; BD Biosciences) and expressed as the percentage of cells in each population (viable, Annexin $\mathrm{V}^{-} / \mathrm{PI}^{-}$; early apoptotic, Annexin $\mathrm{V}^{+} / \mathrm{PI}^{-}$; late apoptotic, Annexin $\mathrm{V}^{+} / \mathrm{PI}^{+}$and necrotic, Annexin $\left.\mathrm{V}^{-} / \mathrm{PI}^{+}\right)$. These data were analyzed by FlowJo v10.0.7 software (FlowJo LLC).

Western blotting. H1650 and A549 cells were harvested, and cytoplasmic and nuclear proteins were isolated using the Proteo JET ${ }^{\mathrm{TM}}$ Cytoplasmic and Nuclear Protein Extraction kit according to the manufacturer's instructions (Fermentas; Thermo Fisher Scientific, Inc.). The Bradford assay was used for protein quantification. Equal amounts of protein (20 $\mu \mathrm{g} /$ lane) were separated via $8 \%$ SDS-PAGE, transferred onto polyvinylidene difluoride membranes (Cytiva) and blocked with blocking buffer containing 5\% skimmed milk in TBS-Tween-20 (0.1\% Tween-20 in 1X TBS) for $1 \mathrm{~h}$ at room temperature. The membranes were incubated with primary antibodies against $\beta$-catenin (1:1,000; cat. no. 9582s; Cell Signaling Technology, Inc.), lamin A $(1: 2,000$; cat. no. 86846s; Cell Signaling Technology, Inc.), Wnt5a (1:800; cat. no. sc-365370; Santa Cruz Biotechnology, Inc.) and GAPDH (1:2,000; cat.no. sc-47724; Santa Cruz Biotechnology, Inc.) overnight at $4^{\circ} \mathrm{C}$. Following primary incubation, membranes were incubated with HRP-conjugated secondary antibodies [anti-rabbit (1:5,000; cat. no. 211-035-109; Jackson ImmunoResearch Laboratories Inc.) or mouse IgG (1:5,000; cat. no. 315-035-048; Jackson ImmunoResearch Laboratories Inc.)] for $1 \mathrm{~h}$ at room temperature. Protein bands were detected using an Enhanced Chemiluminescence System (Pierce: Thermo Fisher Scientific, Inc.). Immunoreactive bands were quantified with the TINA v2.10G software (Raytest Isotopenmegerifte $\mathrm{GmbH}$ ).

$R T-q P C R$. Total RNA was isolated from H1650 and A549 cells using TRIzol ${ }^{\circledR}$ according to the manufacturer's protocol (Invitrogen; Thermo Fisher Scientific, Inc.). Total RNA $(2 \mu \mathrm{g})$ was reverse transcribed into complementary DNA (cDNA) 
A

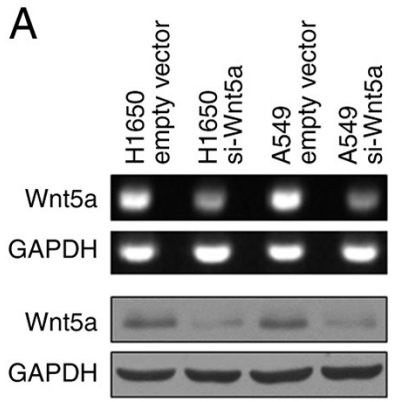

D

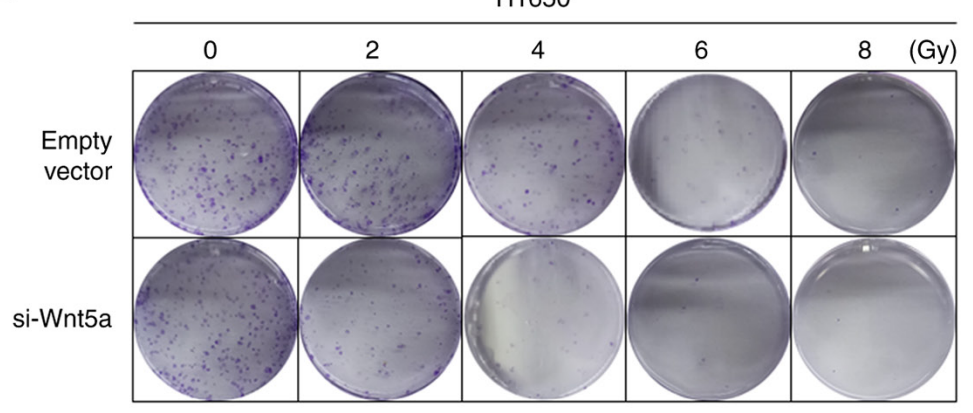

F

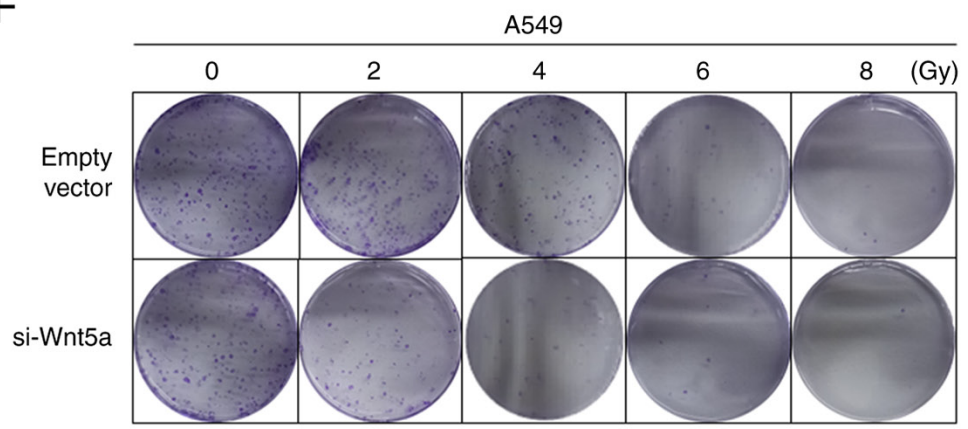

H1650

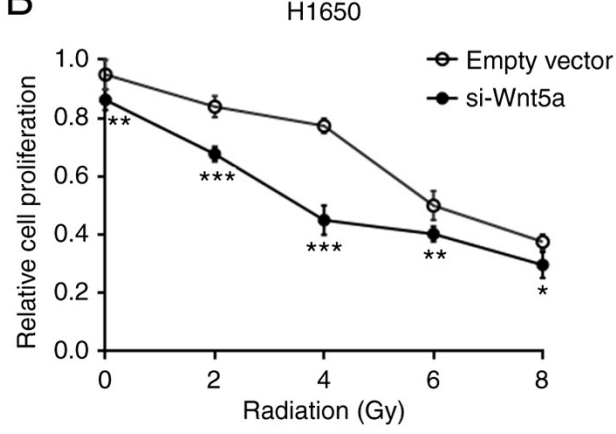

C

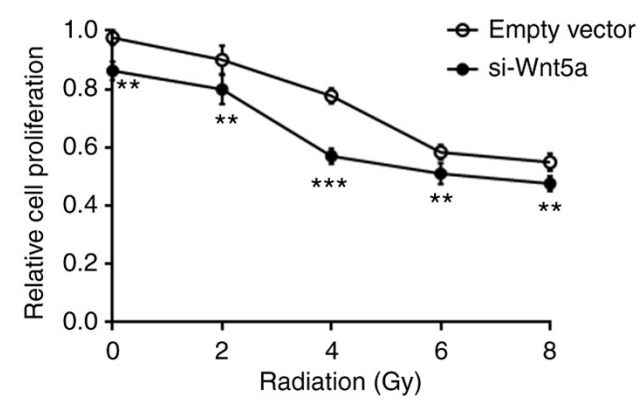

$E$

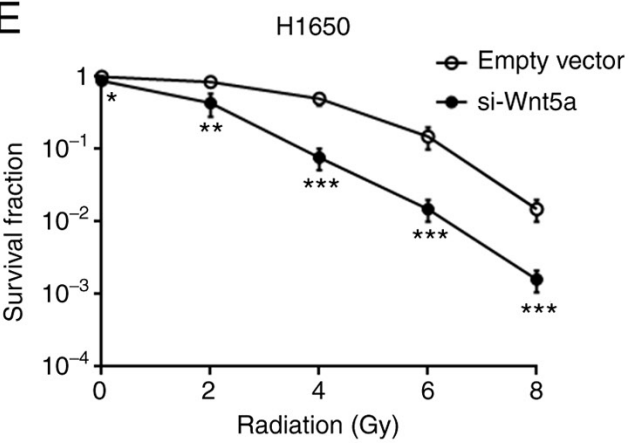

G

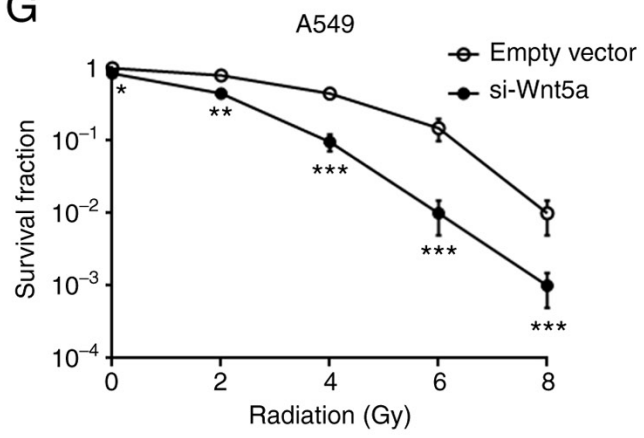

Figure 1. Wnt5a knockdown sensitizes H1650 and A549 cells to irradiation. (A) Silencing of Wnt5a expression in transfected H1650 and A549 cells was verified by reverse-transcription quantitative PCR and immunoblotting, with GAPDH as a loading control. Proliferation of (B) H1650 and (C) A549 cells was determined by MTT assay following irradiation. Surviving fractions of (D and E) H1650 and (F and G) A549 cells treated with a single dose of radiation (0-8 Gy) following transfection with si-Wnt5a or empty vector control (magnification, $\mathrm{x} 10$ ). Data are presented as the mean $\pm \mathrm{SD}$ of three independent repeats. ${ }^{*} \mathrm{P}<0.05,{ }^{* *} \mathrm{P}<0.01$ and ${ }^{* * *} \mathrm{P}<0.001$ vs. empty vector. Wnt5a, wingless-type protein $5 \mathrm{a}$; si, small interfering.

using the First-Strand RT-PCR kit (Promega Corporation). cDNA was subsequently amplified using PCR specific primers for the target genes and GAPDH was amplified as the internal control. The amplification mixture contained 0.5 $\mathrm{U}$ of Taq polymerase (Takara Bio, Inc.). The thermocycling conditions were as follows: $95^{\circ} \mathrm{C}$ for $3 \mathrm{~min} ; 30$ cycles at $95^{\circ} \mathrm{C}$ for $40 \mathrm{sec}$, $58^{\circ} \mathrm{C}$ for $40 \mathrm{sec}$ and $72^{\circ} \mathrm{C}$ for $90 \mathrm{sec}$; final elongation at $72^{\circ} \mathrm{C}$ for $10 \mathrm{~min}$. The primer sequences were as follows: Wnt5a forward, 5'-CGAAGACAGGCATCAAAGAA-3' and reverse, 5'-GCA AAGCGGTAGCCATAGTC-3'; and GAPDH forward, 5'-ACC ACAGTCCATGCCATCAC-3' and reverse, 5'-TCCACCACC CTGTTGCTGTA-3'. RT-qPCR products were electrophoresed via a $1.5 \%$ agarose gel with ethidium bromide. Signals were quantified by densitometric analysis using Labworks Image Acquisition 4.0 software (Analytik Jena US LLC). Statistical analysis was subsequently performed to calculate the gel intensity using Microsoft Excel software 2010 (Microsoft Corporation).
Statistical analysis. Statistical analysis was performed using SPSS v21.0 software (IBM Corp.). All experiments were performed in triplicates and data are presented as the mean \pm SD. Statistical differences were analyzed using one-way ANOVA followed by Tukey's post hoc test. $\mathrm{P}<0.05$ was considered to indicate a statistically significant difference.

\section{Results}

Wnt5 a knockdown enhances irradiation-induced inhibition of NSCLC cell proliferation and colony formation. To determine the effects of Wnt5a knockdown on antitumor radiotherapy in H1650 and A549 cells, MTT assay was performed to assess cell proliferation following radiation alone or combined with transfection with si-Wnt5a or empty vector control. Western blotting and RT-qPCR were performed to detect Wnt5a expression levels (Fig. 1A). Treatment with ionizing radiation (2-8 Gy) inhibited proliferation of H1650 and A549 cells in 


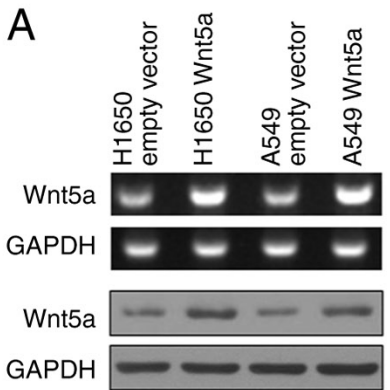

D

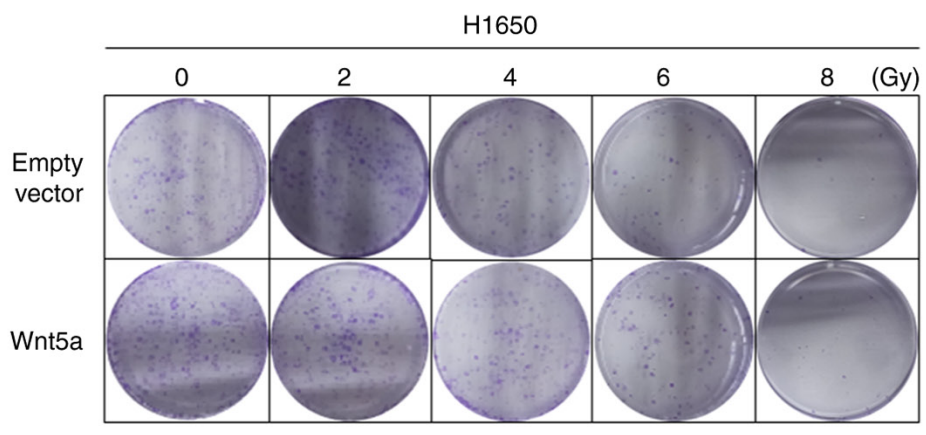

$\mathrm{F}$

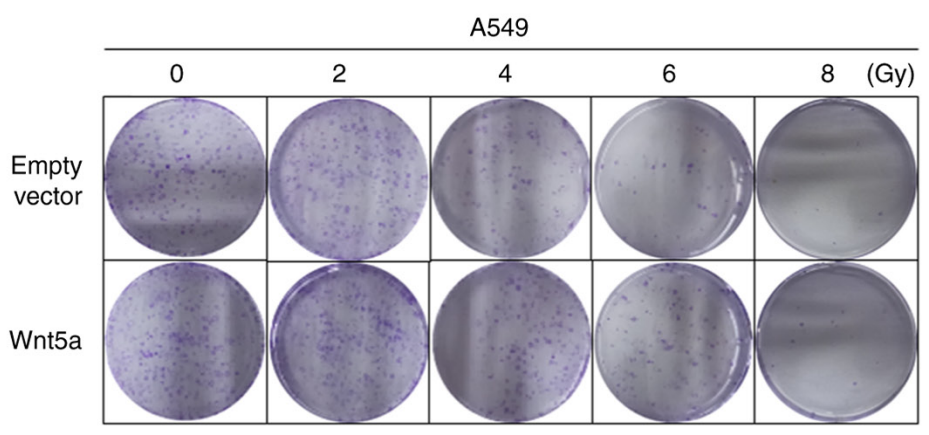

B

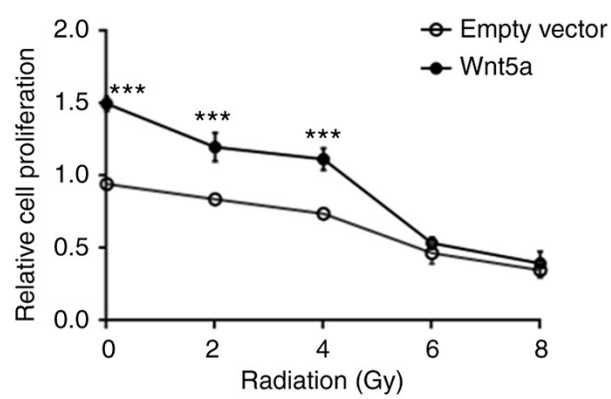

$\mathrm{E}$

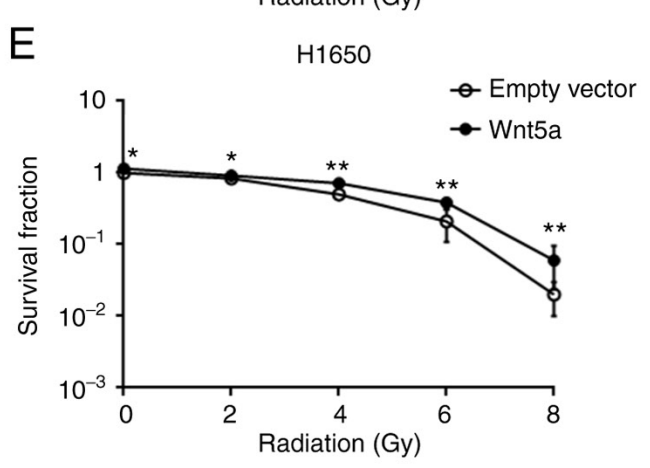

G
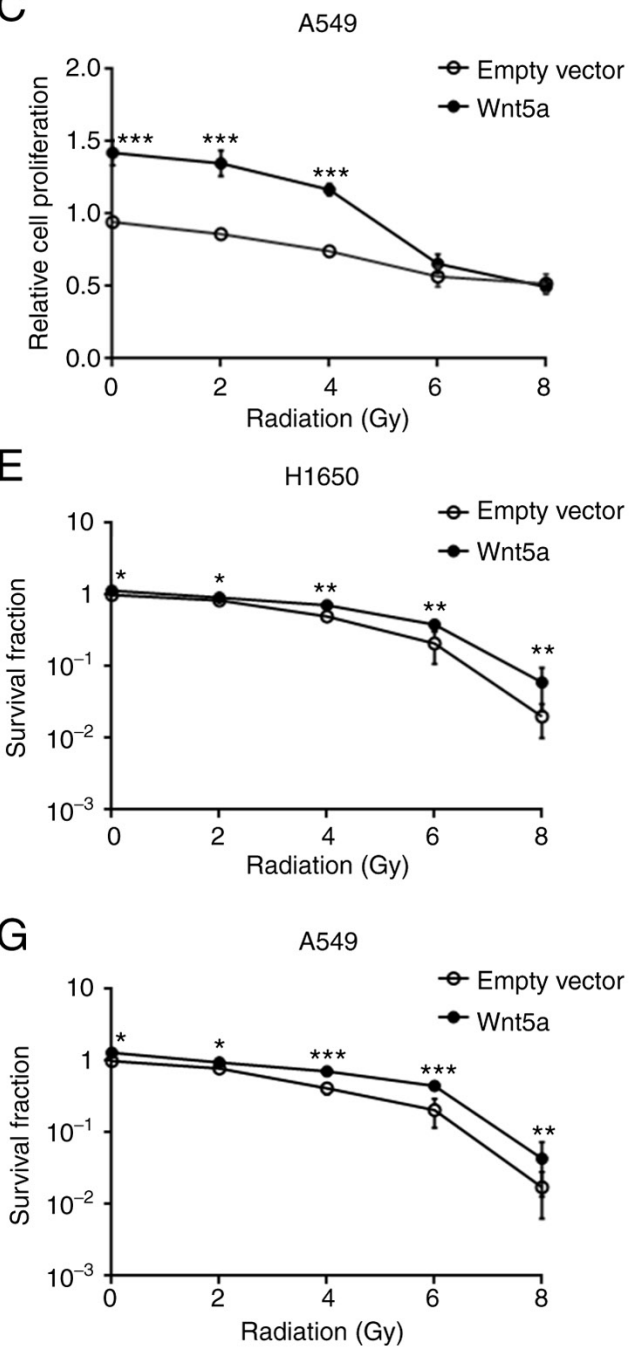

Figure 2. Wnt5a overexpression blocks the inhibitory effect of irradiation on $\mathrm{H} 1650$ and A549 cell proliferation. (A) Overexpression of Wnt5a in transfected H1650 and A549 cells was confirmed by reverse-transcription quantitative PCR and immunoblotting, with GAPDH as a loading control. Proliferation of (B) H1650 and (C) A549 cells was determined by MTT assay following irradiation. Surviving fractions of (D and E) H1650 and (F and G) A549 cells were treated with a single dose of radiation (0-8 Gy) following transfection with Wnt5a or empty vector control (magnification, x10). Data are presented as the mean \pm SD of three independent repeats. ${ }^{*} \mathrm{P}<0.05,{ }^{* *} \mathrm{P}<0.01$ and ${ }^{* * * *} \mathrm{P}<0.001$ vs. empty vector. Wnt5a, wingless-type protein 5a; si, small interfering.

a dose-dependent manner. Furthermore, Wnt5a knockdown decreased the proliferation of H1650 (Fig. 1B) and A549 (Fig. 1C) cells compared with the control (empty vector). The present study investigated whether Wnt5a affects colony formation of H1650 and A549 cells following radiotherapy. The results demonstrated that cell colony formation was significantly inhibited by radiotherapy and Wnt5a knockdown significantly enhanced this inhibitory effect (Fig. 1D-G). Taken together, these results suggest that combined Wnt5a knockdown and irradiation may improve the inhibitory effect on NSCLC cell proliferation.

Overexpression of Wnt5a reverses irradiation-induced inhibition of NSCLC cell proliferation and colony formation. The effect of overexpressing Wnt5a and irradiation on proliferation of $\mathrm{H} 1650$ and A549 cells was investigated. Equal amounts of H1650 and A549 cells transfected with Wnt5a or empty vector control were analyzed via western blotting and RT-qPCR (Fig. 2A). The results demonstrated that overexpression of Wnt5a increased cell proliferation following irradiation at 2 or 4 Gy compared with the empty vector control (Fig. 2B and C). However, no significant differences were observed between the Wnt5a overexpression and empty vector control groups following irradiation at 6 or $8 \mathrm{~Gy}$, suggesting that 6 and 8 Gy doses may be lethal. H1650 (Fig. 2D and E) and A549 (Fig. 2F and G) cells overexpressing Wnt5a were treated with radiotherapy; radiation significantly inhibited colony formation, while overexpression of Wnt5a significantly decreased this inhibitory effect. Collectively, these results suggest that overexpression of Wnt5a attenuated the radiotherapeutic effect on NSCLC cells.

Wnt5a knockdown increases irradiation-induced apoptosis in NSCLC cells. To determine whether Wnt5a knockdown sensitizes H1650 and A549 cells to irradiation-induced apoptosis, cells were transfected with si-Wnt5a and subsequently irradiated with either 0 or $4 \mathrm{~Gy}$. After $24 \mathrm{~h}$, the percentage of apoptotic cells was determined via Annexin V/PI staining 
A
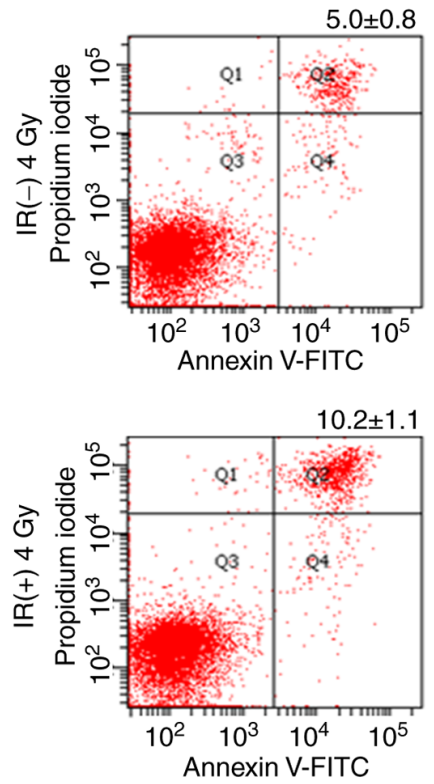

B

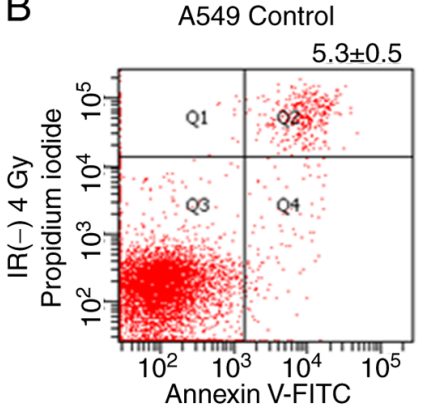

$6.8 \pm 0.6$

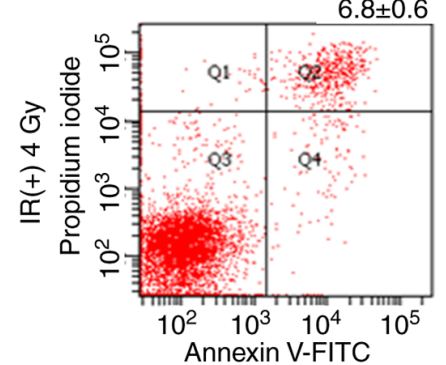

H1650 si-Wnt5a

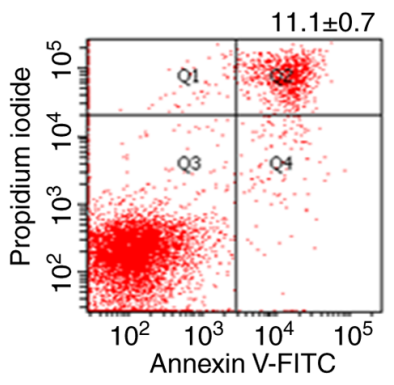

$16.2 \pm 1.4$

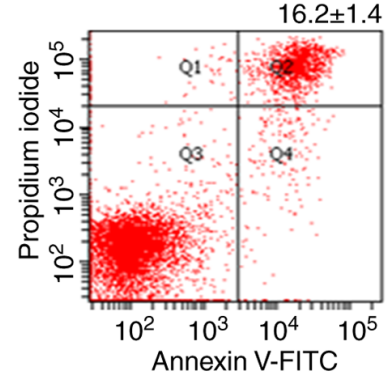

A549 si-Wnt5a

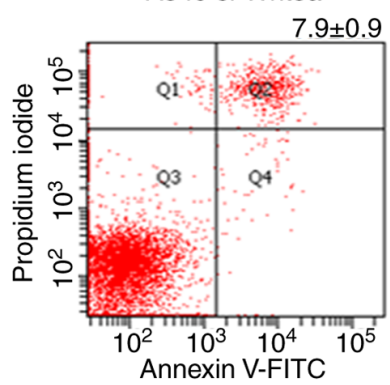

$13.8 \pm 1.2$

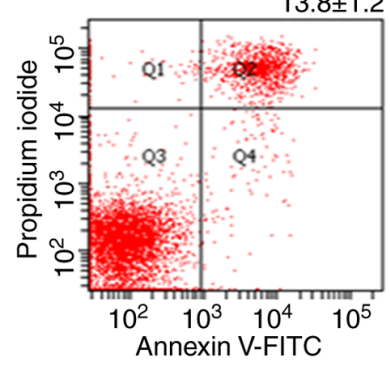

H1650
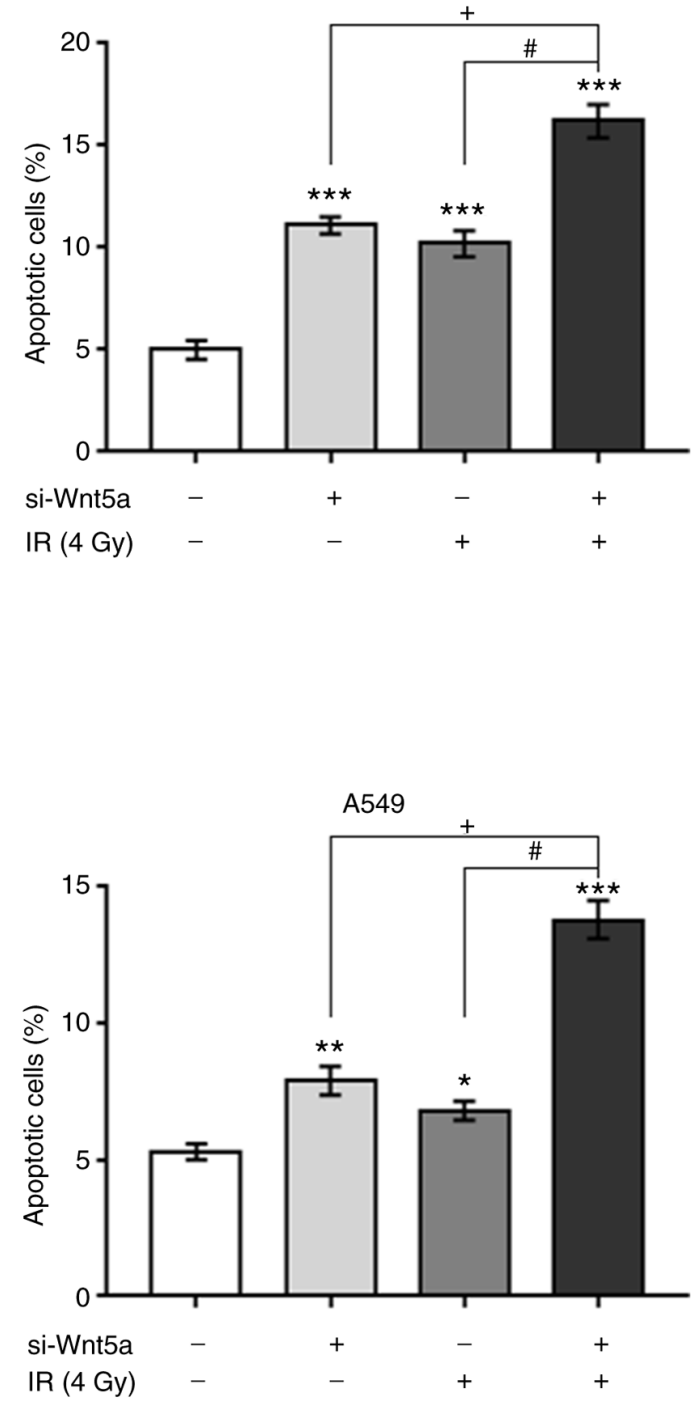

Figure 3. Wnt5a knockdown sensitizes H1650 and A549 cells to IR-induced apoptosis. Apoptosis was detected using Annexin V staining in (A) H1650 and (B) A549 non-small cell lung cancer cells. The proportion of early and late apoptotic cells is shown in the histogram. Apoptosis was significantly higher in the combined Wnt5a suppression and IR group compared with other groups. Data are presented as the mean $\pm \mathrm{SD}$ of three independent repeats. ${ }^{*} \mathrm{P}<0.05$, ${ }^{* *} \mathrm{P}<0.01$ and ${ }^{* * *} \mathrm{P}<0.001$ vs. control; ${ }^{+} \mathrm{P}<0.05$ vs. si-Wnt5a; ${ }^{*} \mathrm{P}<0.05$ vs. IR. Wnt5a, wingless-type protein $5 \mathrm{a}$; si, small interfering; IR, irradiation.

(Fig. 3). The apoptosis of H1650 and A549 cells following Wnt5a knockdown or irradiation alone significantly increased compared with control cells. In addition, combination of Wnt5a knockdown and irradiation further increased apoptosis. Taken together, these results suggest that Wnt5a knockdown sensitized NSCLC cells to irradiation-induced apoptosis.

Overexpression of Wnt5a decreases irradiation-induced apoptosis in NSCLC cells. To determine whether overexpression of Wnt5a affects irradiation-induced apoptosis, H1650 and A549 cells were transfected with Wnt5a or empty vector control following irradiation at 0 or 4 Gy (Fig. 4). The results demonstrated that overexpression of Wnt5a significantly decreased the apoptosis of H1650 and A549 cells compared with the control group. In addition, irradiation (4 Gy) increased the apoptosis of both H1650 and A549 cells; this effect was reversed following overexpression of Wnt5a. Collectively, these results suggest that overexpression of Wnt5a attenuated irradiation-induced apoptosis in NSCLC cells.

$\beta$-catenin expression following Wnt5a knockdown and/or irradiation in NSCLC cells. To determine whether Wnt5a knockdown and irradiation inhibit proliferation and induce apoptosis of NSCLC cells via the $\beta$-catenin pathways, the 
A
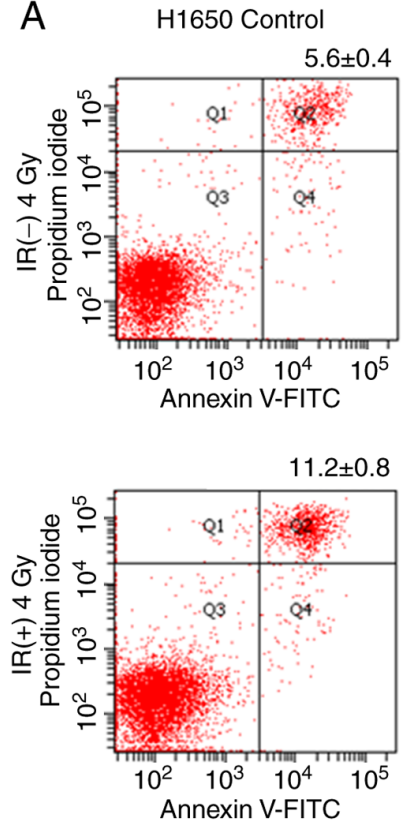

B
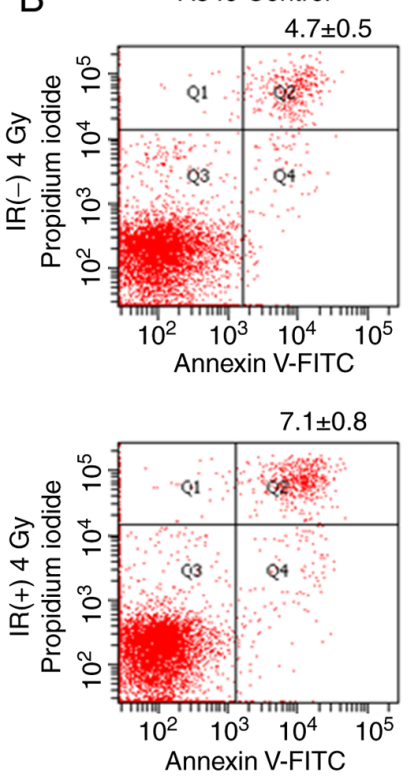

H1650 Wnt5a

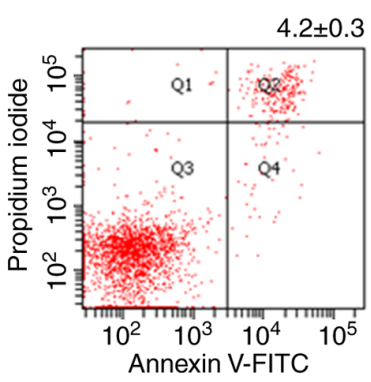

$5.1 \pm 0.6$

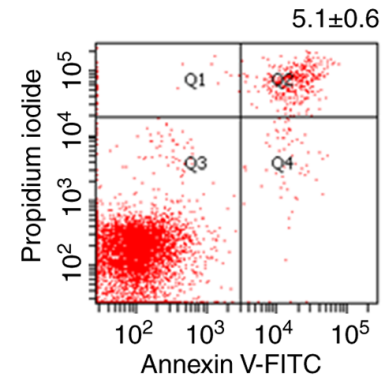

A549 Wnt5a
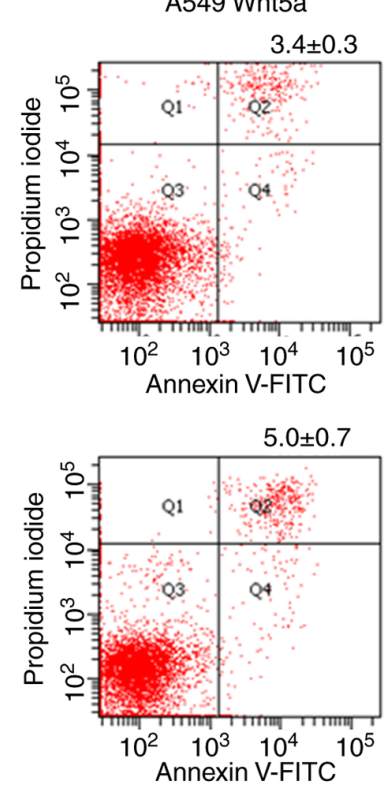

H1650
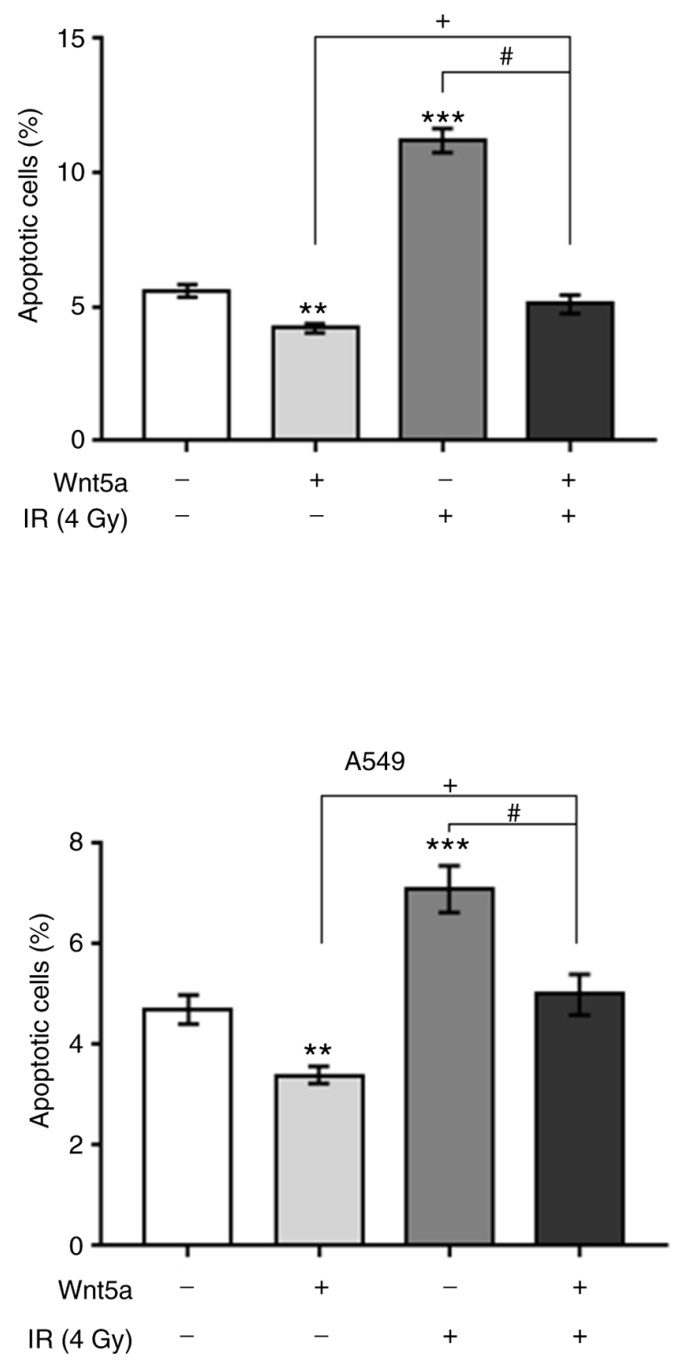

Figure 4. Wnt5a overexpression decreases IR-induced H1650 and A549 cell apoptosis. Apoptosis was detected by Annexin V staining in (A) H1650 and (B) A549 non-small cell lung cancer cells. The proportion of early and late apoptotic cells is shown in the histogram. Data are presented as the mean \pm SD of three independent repeats. ${ }^{* *} \mathrm{P}<0.01$, and ${ }^{* * * *} \mathrm{P}<0.001$ vs. control; ${ }^{+} \mathrm{P}<0.05$ vs. Wnt5a; ${ }^{*} \mathrm{P}<0.05$ vs. IR. Wnt5a, wingless-type protein $5 \mathrm{a}$; IR, irradiation.

cytoplasm and nucleus were separated and $\beta$-catenin expression was detected via western blotting (Figs. 5 and S1). Cytoplasmic $\beta$-catenin expression was higher following Wnt5a knockdown or irradiation in H1650 and A549 cells compared with the control cells. Combined Wnt5a knockdown and irradiation was further enhanced the expression of $\beta$-catenin. Conversely, nuclear $\beta$-catenin expression was reduced by the combination of Wnt5a knockdown and irradiation in H1650 and A549 cells.

$\beta$-catenin expression following overexpression of Wnt5a and/or irradiation in NSCLC cells. The effects of overexpressing Wnt5a and irradiation on cytoplasmic and nuclear expression of $\beta$-catenin in NSCLC cells were investigated (Figs. 6 and S2). Western blot analysis revealed that overexpression of
Wnt5a decreased cytoplasmic but increased nuclear $\beta$-catenin expression in $\mathrm{H} 1650$ and A549 cells. In addition, irradiation treatment increased cytoplasmic and decreased nuclear $\beta$-catenin expression in both $\mathrm{H} 1650$ and A549 cells. Notably, overexpression of Wnt5a reversed the irradiation-induced alterations in cytoplasmic and nuclear $\beta$-catenin expression in H1650 and A549 cells. Taken together, these results suggested that overexpression of Wnt5a may cause translocation of $\beta$-catenin from the cytoplasm to the nucleus in NSCLC cells.

si- $\beta$-catenin reverses activation of NSCLC cell proliferation caused by overexpression of Wnt5a. To determine the role of the $\beta$-catenin pathway in NSCLC cell proliferation induced by overexpression of Wnt5a and irradiation, H1650 and 
A

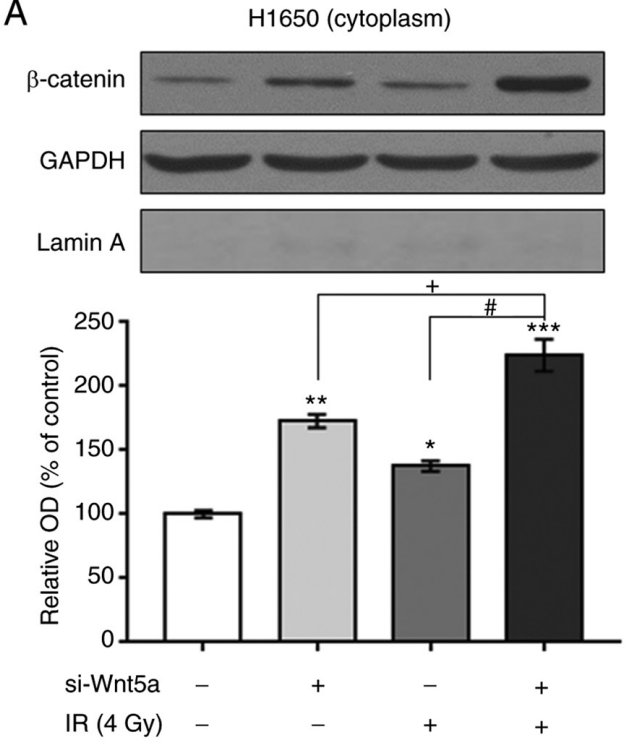

C
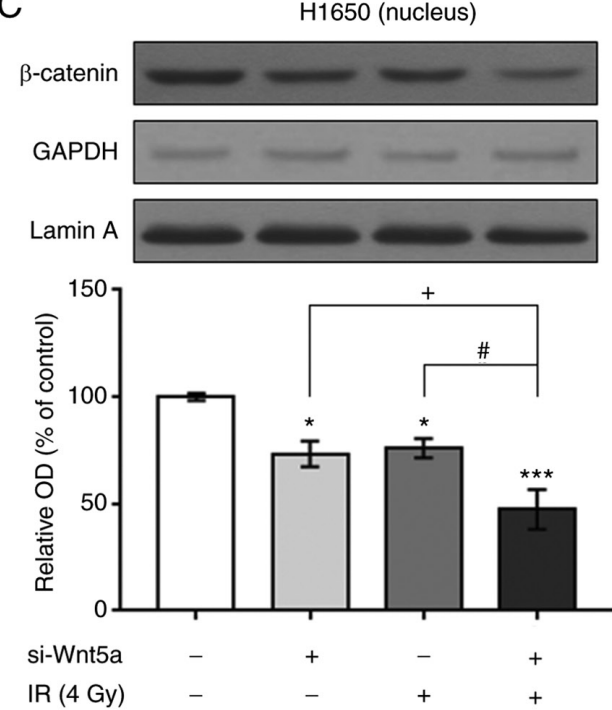

B

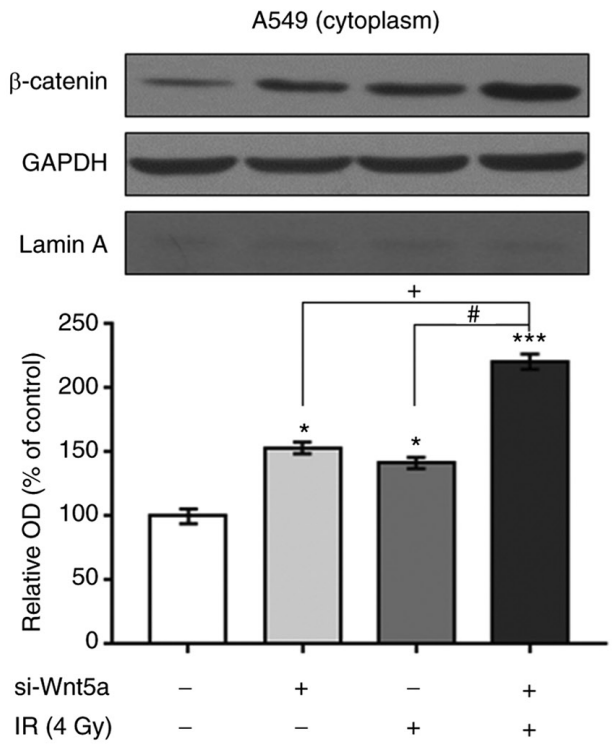

D
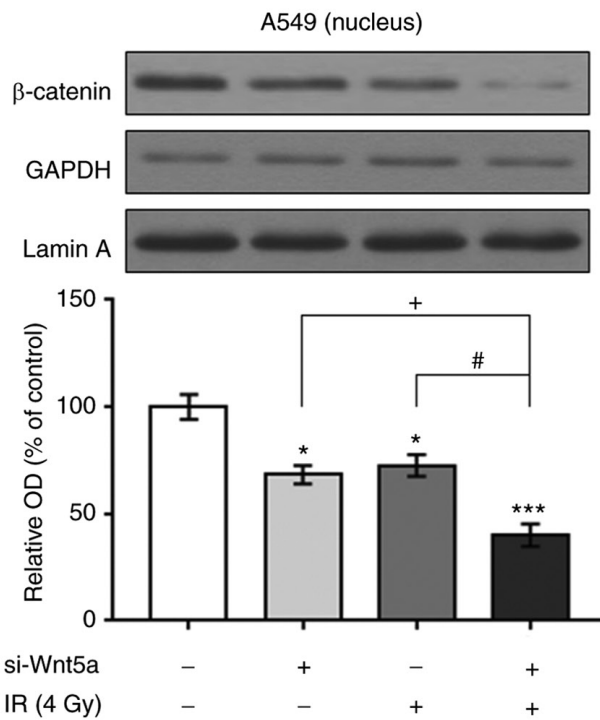

Figure 5. Effect of Wnt5a knockdown and/or IR on expression of $\beta$-catenin in H1650 and A549 NSCLC cells. The expression levels of (A and B) cytoplasmic and (C and D) nuclear $\beta$-catenin were determined by western blot analysis. GAPDH was used as a cytoplasmic control; lamin A was used as a nuclear internal control. Data are presented as the mean $\pm \mathrm{SD}$ of three independent repeats. ${ }^{*} \mathrm{P}<0.05,{ }^{* *} \mathrm{P}<0.01$ and ${ }^{* * *} \mathrm{P}<0.001$ vs. control; ${ }^{+} \mathrm{P}<0.05$ vs. si-Wnt5a; ${ }^{*} \mathrm{P}<0.05$ vs. IR. Wnt5a, wingless-type protein 5a; si, small interfering; IR, irradiation; OD, optical density.

A549 cells were treated with siRNA for $\beta$-catenin knockdown. Knockdown of $\beta$-catenin was confirmed by western blotting and RT-qPCR (Fig. S3). Overexpression of Wnt5a blocked the irradiation-induced decrease in NSCLC cell proliferation (Figs. 7 and S4). In addition, si- $\beta$-catenin reversed the promotion of NSCLC cell proliferation due to combined Wnt5a overexpression and irradiation. Collectively, these results suggest that the $\beta$-catenin pathway may be a mediator of Wnt5a overexpression- and irradiation-induced increases in proliferation and decreases in apoptosis of NSCLC cells.

\section{Discussion}

Wnt5a expression is upregulated in NSCLC cells (18) and regulates several biological events associated with tumor growth, EMT and metastasis of NSCLC cells (9). It has also been reported that overexpression of $\mathrm{Wnt} 5 \mathrm{a}$ increases colony formation, migration and invasion $(12,19)$. Thus, to assess whether alterations of Wnt5a expression affected the response of NSCLC cell lines to radiotherapy, the present study knocked down or overexpressed Wnt5a in H1650 and A549 cells. The results demonstrated that Wnt5a knockdown combined with irradiation decreased proliferation and induced apoptosis of NSCLC cells more than irradiation or Wnt5a knockdown alone. Conversely, overexpression of Wnt5a blocked irradiation-induced apoptosis. These findings suggest that Wnt5a expression served a valuable role in the radiotherapeutic treatment of NSCLC.

Wnt5a signaling comprises non-canonical ( $\beta$-cateninindependent) and canonical ( $\beta$-catenin-dependent) pathways (20). $\beta$-catenin signaling serves an important role in regulating the transcription of several oncogenes, such as cyclin D1 and c-Myc $(21,22)$; thus, different types of cancer exhibit aberrant activation of this signaling pathway $(23,24)$. 
A
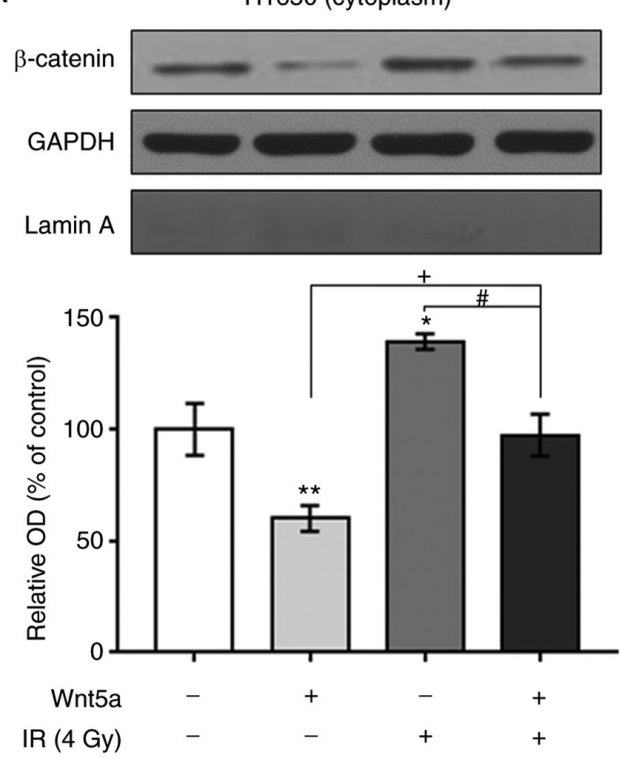

C
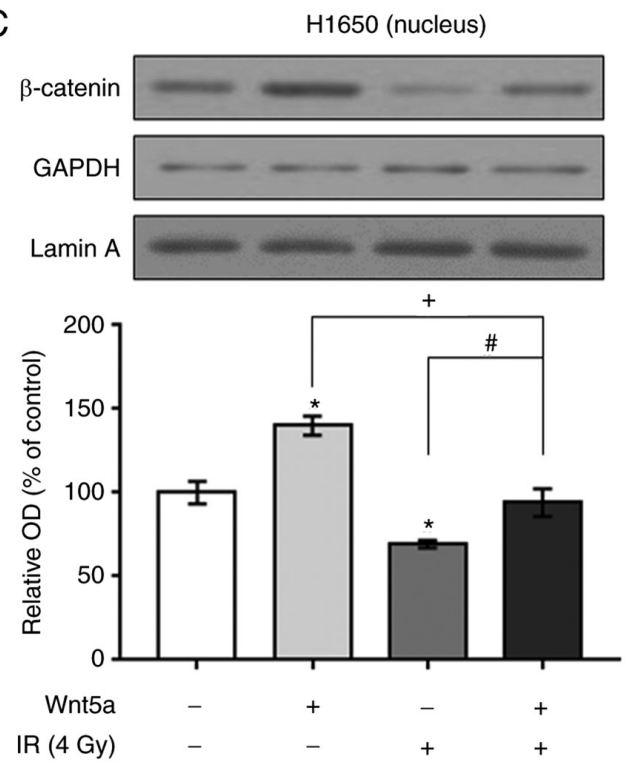

B
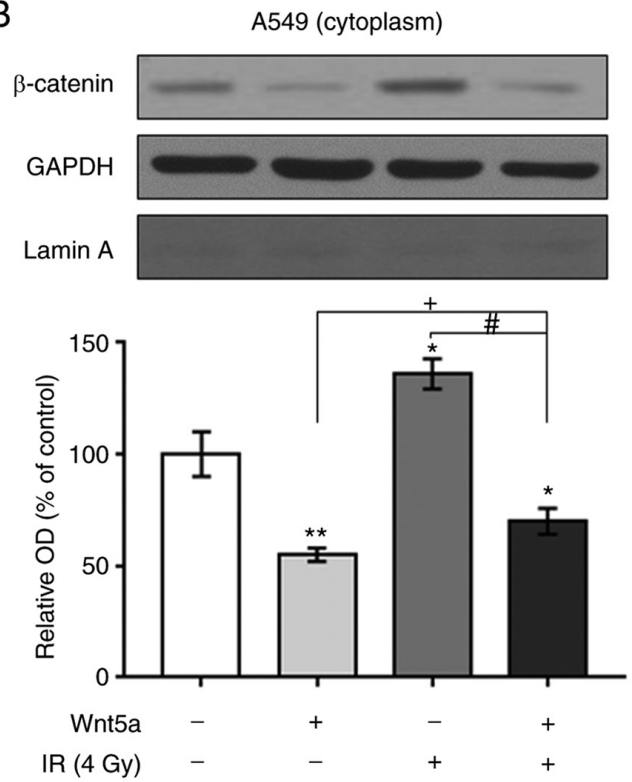

D
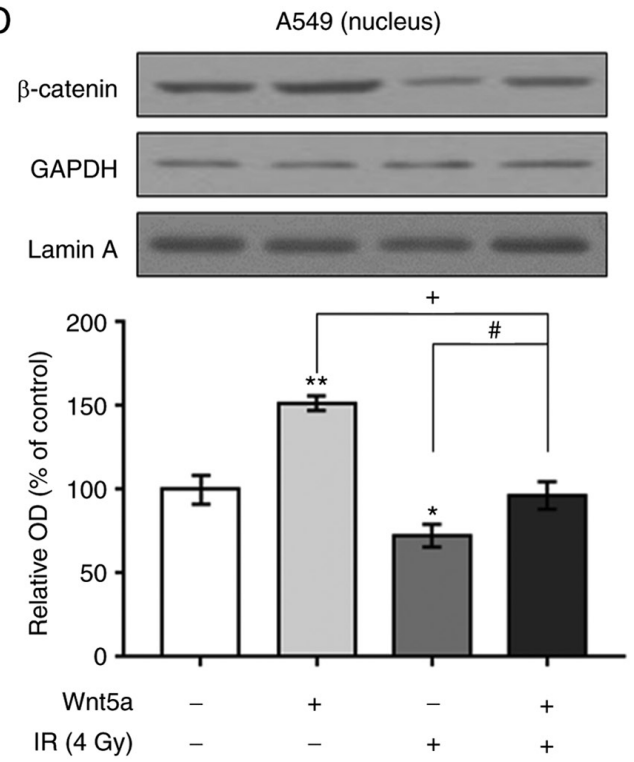

Figure 6. Effect of Wnt5a overexpression and/or IR on expression of $\beta$-catenin in H1650 and A549 NSCLC cells. The expression levels of (A and B) cytoplasmic and $(\mathrm{C}$ and $\mathrm{D})$ nuclear $\beta$-catenin were determined using western blot analysis. GAPDH was used as a cytoplasmic control; lamin A was used as a nuclear internal control. Data are presented as the mean $\pm \mathrm{SD}$ of three independent repeats. ${ }^{*} \mathrm{P}<0.05$ and ${ }^{* * *} \mathrm{P}<0.01$ vs. control; ${ }^{+} \mathrm{P}<0.05$ vs. si-Wnt5a; ${ }^{*} \mathrm{P}<0.05$ vs. IR. Wnt5a, wingless-type protein 5a; IR, irradiation; OD, optical density; si, small interfering.

Activated $\mathrm{Wnt} / \beta$-catenin signaling pathway has been shown to induce translocation of $\beta$-catenin from the cytoplasm to the nucleus $(25,26)$, thus promoting the initiation of EMT, tumor invasion, and metastasis (14,27-29). The present study demonstrated that the combination of Wnt5a knockdown and irradiation decreased nuclear but increased cytoplasmic $\beta$-catenin expression in NSCLC cells. These findings support the hypothesis that the combination of Wnt5a knockdown and irradiation decreases translocation of $\beta$-catenin from the cytoplasm to the nucleus, thus inhibiting NSCLC cell proliferation and enhancing apoptosis.

A previous study reported that Wnt5a plays a key role in regulating NSCLC cell migration and invasion by activating $\beta$-catenin-dependent canonical Wnt signaling (12). Consistent with this finding, the results of the present study demonstrated that Wnt5a knockdown increased NSCLC cell apoptosis. In addition, overexpression of Wnt5a attenuated the killing effect of radiation therapy on NSCLC cells, whereas si- $\beta$-catenin antagonized Wnt5a overexpression-induced proliferation of NSCLC cells. Increasing evidence suggest that the $\mathrm{Wnt} / \beta$-catenin pathway is associated with radioresistance of cancer cells $(7,30)$. The enhanced nuclear translocation of $\beta$-catenin was more evident in radioresistance cells (31-33). Consistent with these findings, the present study demonstrated that Wnt5a knockdown decreased nuclear $\beta$-catenin expression, whereas overexpression of Wnt5a enhanced nuclear $\beta$-catenin expression. Taken together, these results suggest that the Wnt5a/ $\beta$-catenin pathway may exert a radiosensitizing effect in NSCLC.

In conclusion, the present study demonstrated that Wnt5a knockdown in combination with irradiation inhibited 
A
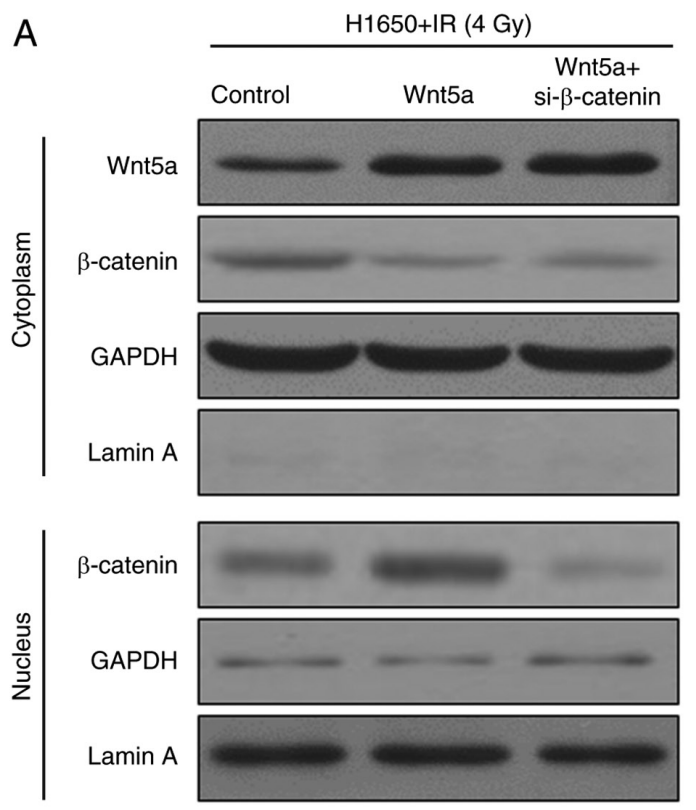

C

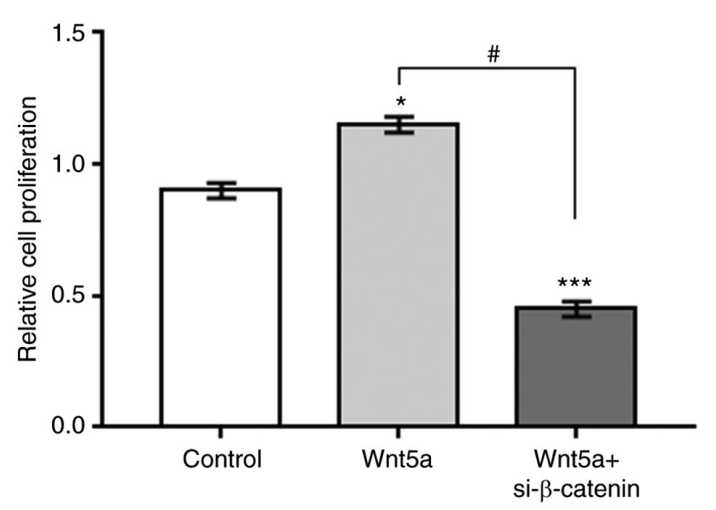

B
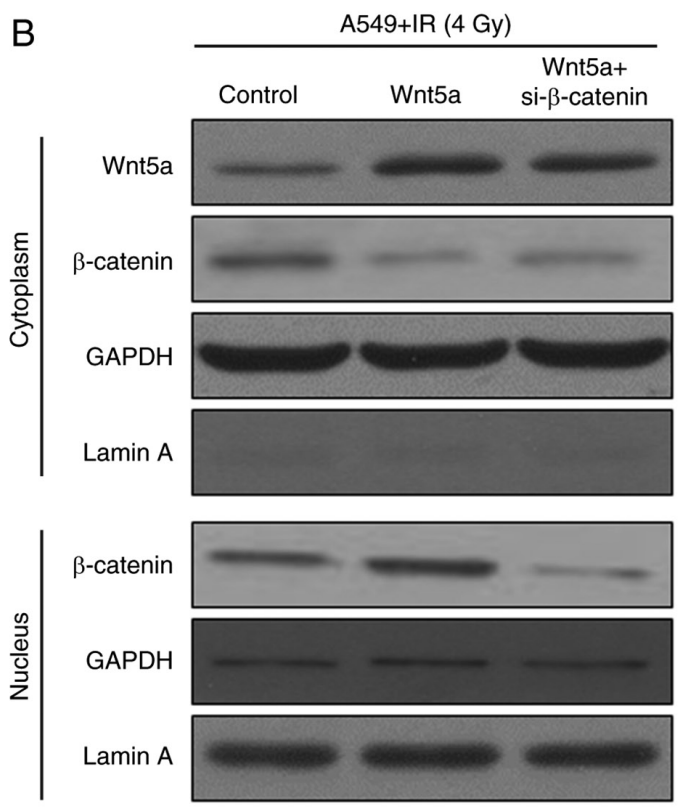

D

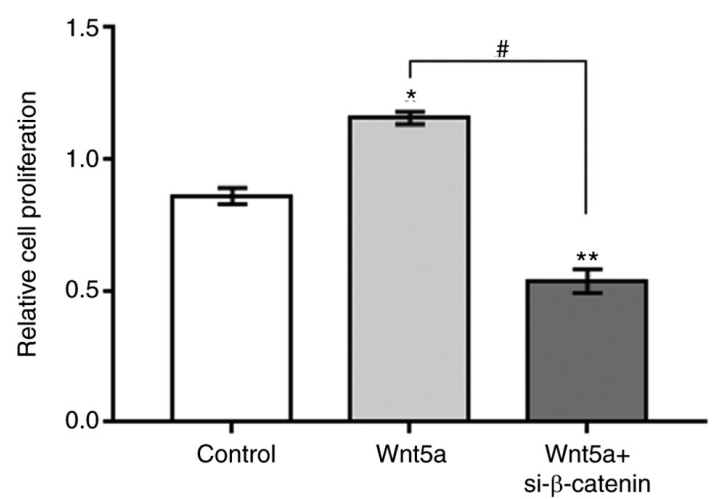

Figure 7. Inactivation of the Wnt/ $\beta$-catenin signaling pathway reverses activation of cell proliferation caused by combined Wnt5a overexpression and irradiation. The expression of $\beta$-catenin in (A) H1650 and (B) A549 cells with Wnt5a overexpression and/or $\beta$-catenin knockdown was determined using western blot analysis. Proliferation of (C) $\mathrm{H} 1650$ and (D) A549 cells with $\beta$-catenin knockdown and/or Wnt5a overexpression was determined by MTT assay following irradiation (4 Gy). Data are presented as the mean $\pm \mathrm{SD}$ of three independent repeats. ${ }^{*} \mathrm{P}<0.05,{ }^{* *} \mathrm{P}<0.01$ and ${ }^{* * * *} \mathrm{P}<0.001$ vs. control; ${ }^{*} \mathrm{P}<0.05$ vs. Wnt5a. Wnt5a, wingless-type protein 5a; si, small interfering; IR, irradiation.

proliferation and induced apoptosis of NSCLC cells; these effects were reversed following overexpression of Wnt5a. In addition, Wnt5a influenced the susceptibility of NSCLC cells to radiotherapy via activation of $\beta$-catenin-dependent canonical Wnt signaling. Thus, Wnt5a gene therapy may enhance the therapeutic effect of radiation for the treatment of NSCLC.

\section{Acknowledgements}

Not applicable.

\section{Funding}

The present work was supported by The General Program (grant nos. 817368 and 819MS135) and Youth Project (both Department of Science and Technology; grant no. 819QN359) and The Regional Science Foundation Program (National Natural Science Foundation; grant no. 81860414).

\section{Availability of data and materials}

All data generated or analyzed during this study are included in this published article.

\section{Authors' contributions}

JL, SX and XX conceptualized and designed the study. JL, SX, XW, HD and LHW acquired the data and drafted the manuscript. JL, SX, XW, HD and LHW performed data analysis. SX and XX wrote the manuscript. JL, SX, XW, HD and $\mathrm{XX}$ revised the manuscript. JL, SX and XX confirm the authenticity of all the raw data. All authors read and approved the final manuscript.

\section{Ethics approval and consent to participate}

Not applicable. 


\section{Patient consent for publication}

Not applicable.

\section{Competing interests}

The authors declare that they have no competing interests.

\section{References}

1. Sung H, Ferlay J, Siegel RL, Laversanne M, Soerjomataram I, Jemal A and Bray F: Global cancer statistics 2020: GLOBOCAN estimates of incidence and mortality worldwide for 36 cancers in 185 countries. CA Cancer J Clin 71: 209-249, 2021.

2. Jemal A, Bray F, Center MM, Ferlay J, Ward E and Forman D: Global cancer statistics. CA Cancer J Clin 61: 69-90, 2011.

3. Harris JP, Murphy JD, Hanlon AL, Le QT, Loo BW Jr and Diehn M: A population-based comparative effectiveness study of radiation therapy techniques in stage III non-small cell lung cancer. Int J Radiat Oncol Biol Phys 88: 872-884, 2014.

4. Kim E, Song C, Kim MY and Kim JS: Long-term outcomes after salvage radiotherapy for postoperative locoregionally recurrent non-small-cell lung cancer. Radiat Oncol J 35: 55-64, 2017.

5. Palayoor ST, Macklis RM, Bump EA and Coleman CN: Modulation of radiation-induced apoptosis and G2/M block in murine T-lymphoma cells. Radiat Res 141: 235-243, 1995.

6. Ning S and Knox SJ: Arrest and death by apoptosis of HL60 cells irradiated with exponentially decreasing low-dose-rate gamma radiation. Radiat Res 151: 659-669, 1999.

7. Lee SB, Gong YD, Park YI and Dong MS: 2,3,6-Trisubstituted quinoxaline derivative, a small molecule inhibitor of the Wnt/ beta-catenin signaling pathway, suppresses cell proliferation and enhances radiosensitivity in A549/Wnt2 cells. Biocchem Biophys Res Commun 431: 746-752, 2013.

8. Stewart DJ: Wnt signaling pathway in non-small cell lung cancer J Natl Cancer Inst 106: djt356, 2014.

9. Bo H, Zhang S, Gao L, Chen Y, Zhang J, Chang X and Zhu M: Upregulation of Wnt5a promotes epithelial-to-mesenchymal transition and metastasis of pancreatic cancer cells. BMC Cancer 13: 496, 2013.

10. Lee GT: Prostate cancer bone metastases acquire resistance to androgen deprivation via WNT5A-mediated BMP-6 induction. Br J Cancer 110: 1634-1644, 2014.

11. Kanzawa M, Semba S, Hara S, Itoh T and Yokozaki H: WNT5A is a key regulator of the epithelial-mesenchymal transition and cancer stem cell properties in human gastric carcinoma cells. Pathobiology 80: 235-244, 2013.

12. Wang B, Tang Z, Gong H, Zhu L and Liu X: Wnt5a promotes epithelial-to-mesenchymal transition and metastasis in non-small-cell lung cancer. Biosci Rep 37: BSR20171092, 2017.

13. Mokhtari RB, Homayouni TS, Baluch N, Morgatskaya E, Kumar S, Das B and Yeger H: Combination therapy in combating cancer. Oncotarget 8: 38022-38043, 2017.

14. Fang B and Roth JA: The role of gene therapy in combined modality treatment strategies for cancer. Curr Opin Mol Ther 5: 475-482, 2003

15. Yap TA, Omlin A and De Bono JS: Development of therapeutic combinations targeting major cancer signaling pathways. J Clin Oncol 31: 1592-1605, 2013

16. Blagosklonny MV: Analysis of FDA approved anticancer drugs reveals the future of cancer therapy. Cell Cycle 3: 1033-1042, 2004

17. Ahn SJ, Choi C, Choi YD, Kim YC, Kim KS, Oh IJ, Ban HJ, Yoon MS, Nam TK, Jeong JU, et al: Microarray analysis of gene expression in lung cancer cell lines treated by fractionated irradiation. Anticancer Res 34: 4939-4948, 2014
18. Whang YM, Jo U, Sung JS, Ju HJ, Kim HK, Park KH, Lee JW, Koh IS and Kim YH: Wnt5a is associated with cigarette smoke-related lung carcinogenesis via protein kinase C. PLoS One 8: e53012, 2013.

19. Huang Y, Liu G, Zhang B, Xu G, Xiong W and Yang H: Wnt-5a regulates proliferation in lung cancer cells. Oncol Rep 23: $177-181,2010$.

20. Pukrop T and Binder C: The complex pathways of Wnt5a in cancer progression. J Mol Med (Berl) 86: 259-266, 2008.

21. He TC, Sparks AB, Rago C, Hermeking H, Zawel L, Da Costa LT, Morin PJ, Vogelstein B and Kinzler KW: Identification of c-MYC as a target of the APC pathway. Science 281: 1509-1512, 1998.

22. Saegusa $M$, Hashimura $M$, Kuwata $T$, Hamano $M$ and Okayasu I: $\beta$-Catenin simultaneously induces activation of the p53-p21WAF1 pathway and overexpression of cyclin D1 during squamous differentiation of endometrial carcinoma cells. Am J Pathol 164: 1739-1749, 2004.

23. Anastas JN and Moon RT: WNT signaling pathways as therapeutic targets in cancer. Nat Rev Cancer 13: 11-25, 2013.

24. de Sousa E, Melo F and Vermeulen L: Wnt signaling in cancer stem cell biology. Cancers (Basel) 8: 60, 2016.

25 . Shang $\mathrm{S}$, Hua $\mathrm{F}$ and $\mathrm{Hu} \mathrm{ZW}$ : The regulation of $\beta$-catenin activity and function in cancer: Therapeutic opportunities. Oncotarget 8: 33972-33989, 2017

26. Li XQ, Yang XL, Zhang G, Wu SP, Deng XB, Xiao SJ, Liu QZ, Yao KT and Xiao GH: Nuclear $\beta$-catenin accumulation is associated with increased expression of Nanog protein and predicts poor prognosis of non-small cell lung cancer. J Transl Med 11: $114,2013$.

27. Eger A, Stockinger A, Schaffhauser B, Beug H and Foisner R: Epithelial mesenchymal transition by c-Fos estrogen receptor activation involves nuclear translocation of $\beta$-catenin and upregulation of $\beta$-catenin/lymphoid enhancer binding factor-1 transcriptional activity. J Cell Biol 148: 173-188, 2000.

28. Xu X, Sun PL, Li JZ, Jheon S, Lee CT and Chung JH: Aberrant Wnt $1 / \beta$-catenin expression is an independent poor prognostic marker of non-small cell lung cancer after surgery. J Thorac Oncol 6: 716-724, 2011.

29. Roy LD, Sahraei M, Subramani DB, Besmer D, Nath S, Tinder TL, Bajaj E, Shanmugam K, Lee YY, Hwang SI, et al: MUC1 enhances invasiveness of pancreatic cancer cells by inducing epithelial to mesenchymal transition. Oncogene 30 : 1449-1459, 2011.

30. Woodward WA, Chen MS, Behbod F, Alfaro MP, Buchholz TA and Rosen JM: WNT/beta-catenin mediates radiation resistance of mouse mammary progenitor cells. Proc Natl Acad Sci USA 104: 618-623, 2007.

31. Wang L, Zhang XM, Li Z, Liu XJ, Chai J, Zhang GY and Cheng YF: Overexpression of nuclear $\beta$-catenin in rectal adenocarcinoma is associated with radioresistance. World J Gastroenterol 19: 6876-6882, 2013.

32. Tanaka H, Kawaguchi M, Shoda S, Miyoshi T, Iwasaki R, Hyodo F, Hyodo F, Mori T, Hara A, Tomita H and Matsuo M: Nuclear Accumulation of $\beta$-catenin in cancer stem cell radioresistance and stemness in human colon cancer. Anticancer Res 39: 6575-6583, 2019

33. Luo Y, Li M, Zuo X, Basourakos SP, Zhang J, Zhao J, Han Y, Lin Y, Wang Y, Jiang Y, et al: $\beta$-catenin nuclear translocation induced by HIFl $\alpha$ overexpression leads to the radioresistance of prostate cancer. Int J Oncol 52: 1827-1840, 2018.

his work is licensed under a Creative Commons Attribution-NonCommercial-NoDerivatives 4.0 International (CC BY-NC-ND 4.0) License. 